\title{
Usage of Rapid Prototyping Technique in Customized Craniomaxillofacial Bone Tissue Engineering Scaffold
}

\author{
Dong Han ${ }^{1}$, Jiasheng Dong ${ }^{1 *}$, De Jun $\mathrm{Cao}^{1}$, Zhe-Yuan $\mathrm{Yu}^{1}$, Hua $\mathrm{Xu}^{1}$, \\ Gang Chai ${ }^{1}$, Shen Guo-Xiong ${ }^{1}$ and Song-Tao $\mathrm{Ai}^{2}$ \\ ${ }^{1}$ Department of Plastic and Reconstructive Surgery, Ninth People's Hospital, Medical \\ School of Shanghai Jiao Tong University, Shanghai \\ ${ }^{2}$ Department of Radiology, Ninth People's Hospital, Medical School of Shanghai Jiao Tong \\ University, Shanghai, \\ People's Republic of China
}

\section{Introduction}

Congenital defect, posttraumatic asymmetries, and depressive deformities in craniofacial skeleton are common in the craniomaxillofacial surgical practice. In these patients, the injury or hypoplasty zone and precise shape of the implant that will fill the bone defect must be determined preoperatively, and an appropriate estimate of the quantity of bone needed must be made before plastic surgery. A combination of digital medical technology and tissue engineering has shown great promise for repairing these defects.

Computer-aided design (CAD) and computer-aided manufacturing (CAM) systems can manipulate three-dimensional (3D) computed tomographic (CT) images of bone, using a virtual reality force feedback device. Rapid prototyping (RP) is an exceptional innovation in engineering that has been applied to medicine to build models that provide both visual and tactile information. CAD/CAM and RP techniques allow the generation of scaffolds for cell delivery that are custom-made to fit into given bone defects. Craniomaxillofacial bone is irregular and has a subtle 3D structure, and individualized repair of bone defects is very important. CAD, CAM, laser scanning and RP technologies have therefore been applied in craniomaxillofacial surgery.

The scaffolds employed must fit into the anatomical defect and must have sufficient mechanical integrity as well as a controllable degradation rate. The synthetic biodegradable polymers poly (lactic acid) (PLA), poly (glycolic acid) (PGA) and poly (lactic-co-glycolic acid) (PLGA) have attracted much attention in tissue engineering because of their excellent biocompatibility, ease of fabrication into desired shapes, uniform quality and controllable degradation timescales compared to natural macromolecules.

The cells for bone tissue engineering must be available in large numbers and must be able to express the cartilage and bone phenotypes. Bone marrow stem cells (BMSCs) can differentiate into fibroblastic, osteogenic and adipogenic cells. The method for harvesting these cells is well established, and BMSC lines can be readily propagated for long periods without losing their potency. Many BMSCs can be cultured, enabling fabrication of 
transplantable constructs that are composed of appropriate scaffolds with successful BMSC ingrowth.

Based our previous research work, we developed a novel digital medical support system that allows us to manipulate 3D CT images and develop the prototype of a custom-made scaffold for surgical repair of a craniomaxillofacial bone defect in an animal model. In this chapter, we will describe our workflow of the construction of customized craniomaxillofacial bone tissue engineering scaffold with an example of dog's mandibular condyle.

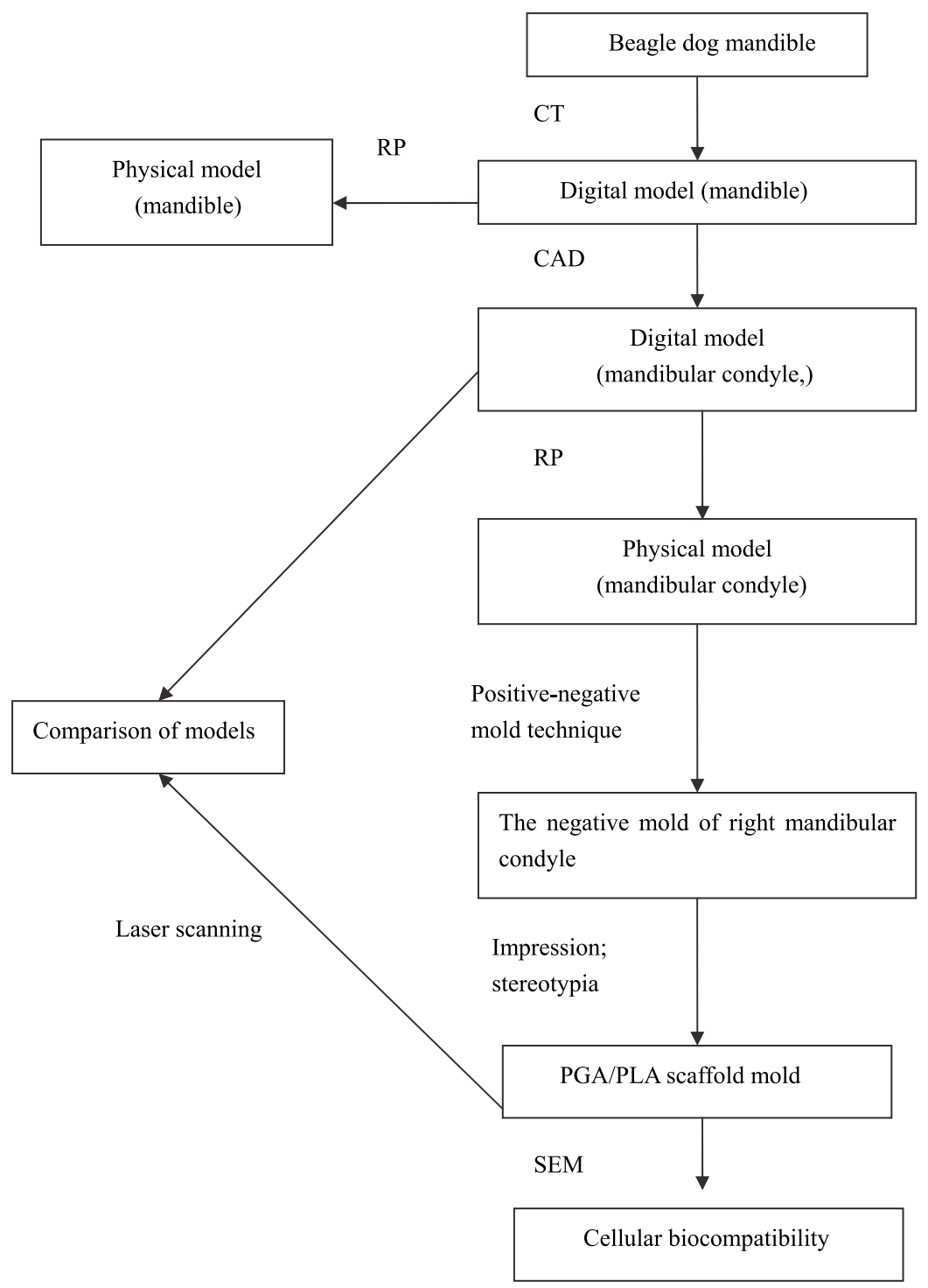

Fig. 1. Flow chart describing the protocol 
In the pilot study, 12-week-old beagle dogs (male, weighing 10-15 kg) were selected. An institutional review committee of Shanghai Jiao Tong University School of Medicine approved all animal study protocols. The animals were examined using 3D CT. For each dog, a model of the mandibular condyle was produced by RP to guide construction of a fitted bone substitute scaffold made of PGA/PLA, which was then seeded with BMSCs. The workflow could be divided into 5 major steps as described in figure 1 .

\section{STEP 1: CAD and RP of the dog mandible}

The mandibles of beagle dogs were examined using a multi-slice CT scanner (GE Medical Systems, Light-Speed16, New York, USA). CT scans were carried out with a slice thickness of $0.625 \mathrm{~mm}(120 \mathrm{kV}, 70 \mathrm{~mA})$. The raw data were exported to Digital Imaging and Communications in Medicine (DICOM) 3.0 format files. With the help of SimMed (PAMI of Shanghai Jiaotong University, Shanghai, China), we imported the formatted images and selected the bone tissue scale (CT threshold, 251-3072) for every slice. A 3D digital model of the mandible (without soft tissue and cartilage) was then reconstructed slice by slice and compiled into a solid geometric model in STL format (Figure 2).

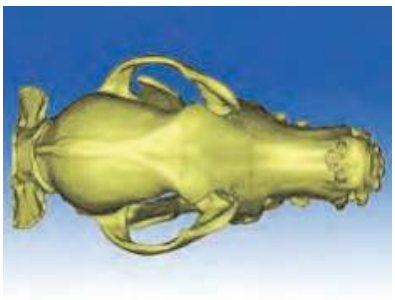

(a)

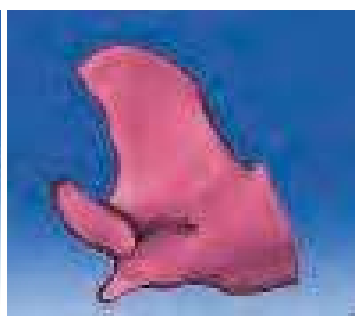

(b)

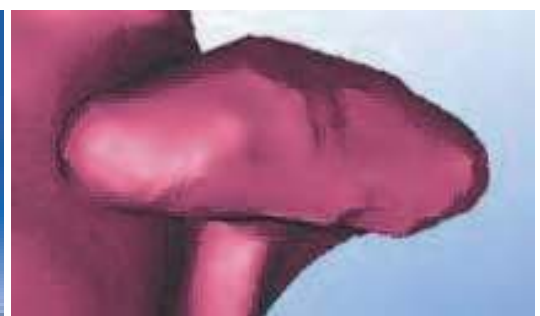

(c)

Fig. 2. Virtual model: (a) 3D reconstruction of the skull; (b) mandibular ramus; and (c) mandibular condyle

The STL files were then imported into Z-Printer 510 (Z Corp Inc., MA, USA). This system enables $3 \mathrm{D}$ printing (3D-P) using resin powder. The process consists of a printer-like computer system that directs the deposition of layers of sealant alternating with layers of resin powder (each $0.1 \mathrm{~mm}$ thick), resulting in the fabrication from CAD data of 3D models of the left mandibular condyle, using layer-by-layer manufacturing (Figure 3). Actually, the detail method of 3D outputting was not important. The keynote procedure here was to have the first positive solid model that was same as which we had reconstructed in cyber world.

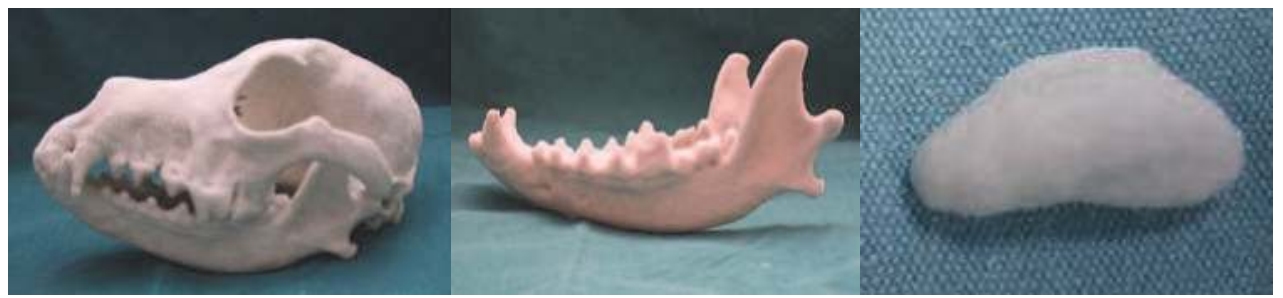

(a) (b)

Fig. 3. (a) Completed RP model: lateral view of the skull. (b) Completed RP model: lateral view of the mandible. (c) Completed RP model: posterior view of the left mandibular condyle 


\section{STEP 2: Fabrication of a negative mould of the mandibular condyle}

The RP model of the mandibular condyle was used as the positive model and was impressed into semisolid-state gypsum or silicone fibrosum, creating a negative mould, which was dried at room temperature. The mould was clamshelled by sectioning two sides and leaving the bottom intact to allow for easy removal of the positive model (Figure 4).

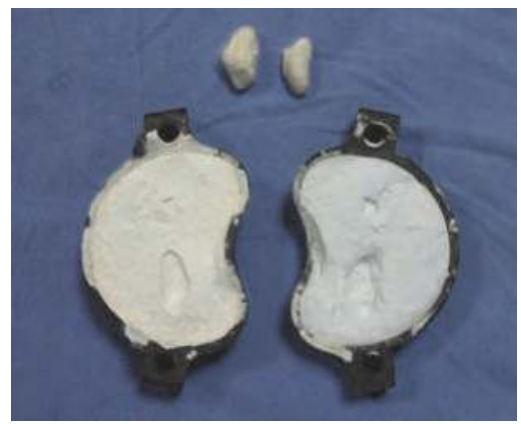

Fig. 4. Negative mould of the left mandibular condyle. gypsum fibrosum mould, open. Rapid prototyped PGA/PLA scaffolds in mandibular condyle bone defect reconstruction

\section{STEP 3: Preparation of the PGA/PLA scaffold}

Unwoven PGA fibres (60 mg; Albany International Research, Albany, NY, USA) were layered into the negative mould and $0.6 \mathrm{ml} 1.5 \%$ PLA (Sigma-Aldrich, St. Louis, MO, USA) was diluted in dichloromethane solvent and added to maintain the scaffold shape. The scaffold was then removed from the mould carefully (Figure 5). Then, the geometry accuracy of the scaffold model was needed to be checked.

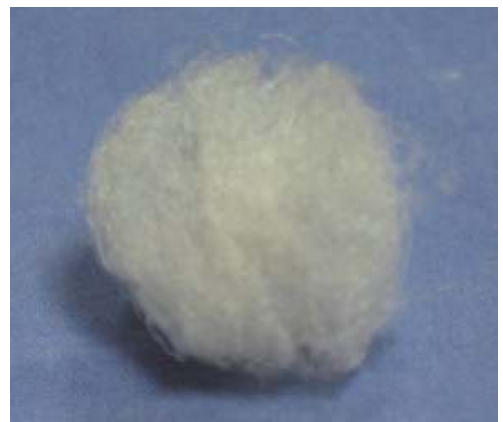

(a)

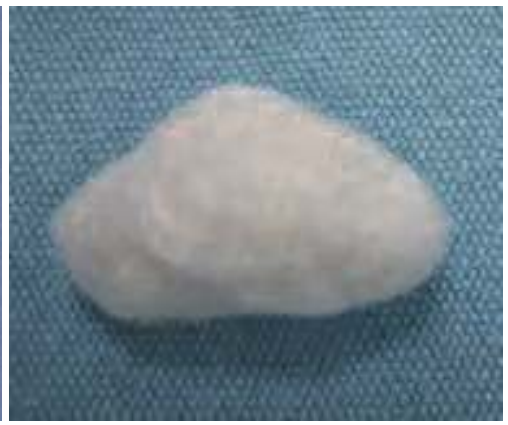

(b)

Fig. 5. (a) Unwoven fibres of PGA. (b) PGA/PLA model scaffold of the left mandibular condyle

\section{STEP 4: Laser scanning of the scaffold model}

A 3D laser surface scanning system (VIVID910 3D, Konica Minolta, Tokyo, Japan) with a Polygon Editing Tool v. 1.03 (Konica Minolta, Tokyo, Japan) was used to acquire the 3D geometric surfaces of the regenerated left mandibular condyle. The scan was performed with a $25 \mathrm{~mm}$ focus camera at a scan distance of $750 \mathrm{~mm}$. Every model was scanned from 
five perpendicular angles, and the scanned images from each model were noise-filtered, smoothed, registered and merged into a single, equidimensional-scale, digital, stereoscopic model in STL format. The left condyle of the CT-reconstructed STL model was put aside as the comparison object. Afterwards, the scan result was finely registered to the CT model using Rapidform2006 (ISUS Ltd, Korea) to match up certain reference points on the geometric surface, ensuring that the two models had the same coordinates. Then, we compared the divergence of the two sample datasets, using the Whole Inspection Model tool in Rapidform2006, which automatically measures the distance $(\mathrm{mm})$ between each corresponding triangle surface on two registered surfaces and displays the measured distances as a coloured chart (Figure 6).

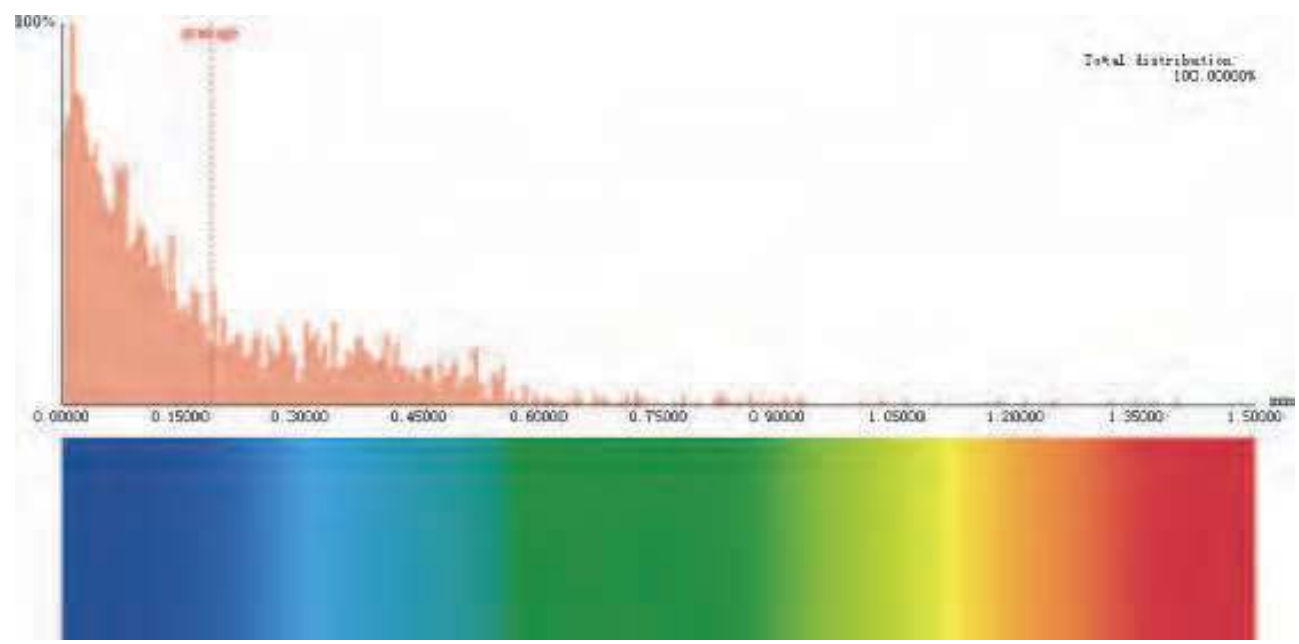

(a)

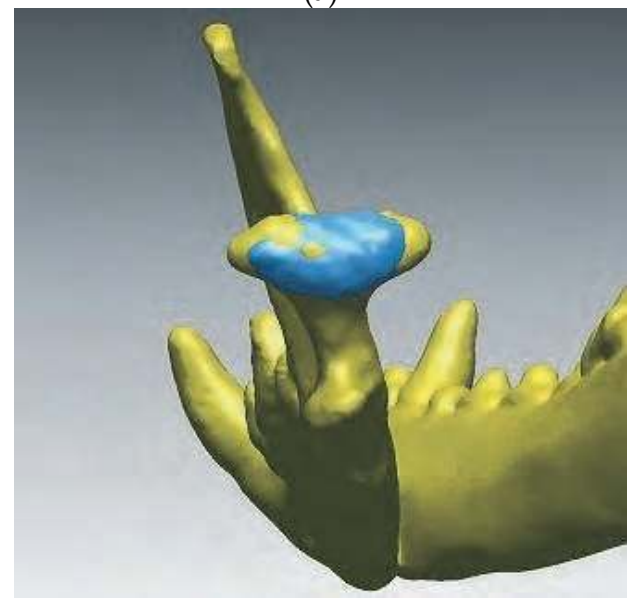

(b)

Fig. 6. (a) Total distribution of scan data. (b) Comparison of the three acquisitions: point clouds obtained by CT and from the laser scanner 


\section{STEP 5: Cellular biocompatibility with the PGA/PLA scaffold in vitro}

The model scaffold was sterilized by soaking in $75 \%$ alcohol and washing three times with phosphate-buffered saline (PBS). This was followed by two washes with Dulbecco's modified Eagle's medium (DMEM; Gibco, USA). Bone marrow aspirates $(5 \mathrm{ml})$ were taken from the iliac crests of beagle dogs. The aspirates were resuspended in $20 \mathrm{ml}$ DMEM with $0.5 \mathrm{ml}$ heparin sodium. The mixture was centrifuged at $1000 \mathrm{rpm}$ for 5 minutes and the supernatant removed. The cell pellets were resuspended, loaded onto Ficoll-Paque PLUS and centrifuged at $1500 \mathrm{rpm}$ for $10 \mathrm{~min}$. Fractions containing low-density mononuclear cells were harvested with a pipette and washed twice with PBS before culturing. The cells were cultured in DMEM supplemented with $10 \%$ fetal bovine serum. The cultures were maintained at $37{ }^{\circ} \mathrm{C}$ in an atmosphere of $5 \%$ CO2. BMSCs at passage $2(2.5 \times 107$ cells in 0.5 $\mathrm{ml}$ ) were evenly dropped onto PGA/PLA scaffolds to form cell/scaffold constructs. These constructs were then cultured in DMEM supplemented with $10 \%$ FBS at $37^{\circ} \mathrm{C}$ in a $5 \% \mathrm{CO} 2$ atmosphere. After 7 days of incubation, cell attachment and matrix production on the polymer were observed via scanning electron microscopy (SEM; JEOL JSM-6360LV, Japan). Post-processed 3D geometric models from laser scanning demonstrated that the mean error between the two samples was $<0.3 \mathrm{~mm}$; moreover, at error $<1 \mathrm{~mm}$, confidence remained at $\geq 95 \%$. For each tolerance level, the degree of deviation was shown as a percentage (Table 1 ). The results indicate that the amount of overlap between the two datasets, expressed as percentages for tolerance levels $0.1,0.3,0.5,0.8$ and $1.00 \mathrm{~mm}$, were $54.01 \%, 77.88 \%, 90.26 \%$, $94.83 \%$ and $95.65 \%$, respectively. SEM showed that BMSCs were able to adhere to the scaffold surface and spread and grow along its fibres. Most of these cells had synthesized and organized abundant extracellular matrices, with which they had created bridges between one another.

\begin{tabular}{cccccc}
\hline $\begin{array}{c}\text { Subjects } \\
(\mathrm{n}=8)\end{array}$ & $\begin{array}{c}1.0 \mathrm{~mm} \\
(\%)\end{array}$ & $\begin{array}{c}0.8 \mathrm{~mm} \\
(\%)\end{array}$ & $\begin{array}{c}0.5 \mathrm{~mm} \\
(\%)\end{array}$ & $\begin{array}{c}0.3 \mathrm{~mm} \\
(\%)\end{array}$ & $\begin{array}{c}0.1 \mathrm{~mm} \\
(\%)\end{array}$ \\
\hline Mean & 95.65 & 94.83 & 90.26 & 77.88 & 54.01 \\
SD & 1.47 & 2.13 & 2.78 & 3.44 & 3.31 \\
Maximum & 97.98 & 97.08 & 93.77 & 82.66 & 59.63 \\
Minimum & 93.45 & 90.63 & 85.81 & 71.28 & 49.27 \\
\hline
\end{tabular}

Table 1. Degree of deviation (\%) at $0.1,0.3,0.5,0.8$ and $1.00 \mathrm{~mm}$

In craniomaxillofacial surgery, morphological characteristics of the bone and relevant mechanisms of injury dictating the complexity and variety of the methods are currently used to repair the bony defect, of which the most important components are restoration of tissue volume and reconstruction of the 3D contour and shape.

New technology such as RP has been widely used in craniomaxillofacial reconstructive surgeries. These technologies have facilitated the transformation of reconstructive surgical practice from complicated, general, and experience based to simple, accurate, and digitalized. Because the structure of the craniofacial skeleton is comparatively delicate and the bone surface is irregular, artificial implant materials cannot be easily molded during operation. When RP is applied for the preoperative design of the implant, the operation time will be effectively shortened and the result will be substantially improved. Moreover, a personalized preoperative design shall make the implant an accurate match for the defect. Aesthetic needs are both met when the defect is corrected. Rapid prototyping is the digitalized technology grounded on theories of discrete and accumulative forming that 
produces the substance layer by layer or point by point. Based on the CT scan data and the CAD model of the substance, the production for the prototype is accurately conducted. With the rapid development of the computer software and hardware and further introduction of mathematics, the CAD/CAM as the importance technology can be applied more widely.

Three-dimensional CT reconstruction was first applied to craniomaxillofacial research and treatment in 1986. Craniofacial skeleton conditions can be found out clearly through threedimensional CT scan. Virtual digital data of CT scan are transferred into a solid threedimensional reconstruction model. Therefore, replication of the deformed state can be interpreted directly, and craniofacial anatomy and periphery relationship can be described in detail. The accuracy of the model, which has been tested by both domestic and international scholars, helps physicians to find out the degree and the specificity of the defect easily, thoroughly, and directly. Thus, the preoperative simulation and the treatment plan are carried out to reduce both the difficulty and the duration of the surgery. With the effective communication between the physician and the patient, consensus is reached and postoperative satisfaction is met. Overall, the three-dimensional reconstruction model is an irreplaceable tool in the contemporary craniomaxillofacial surgery.

Reconstruction of 3D images from CT data has been used for many years to enhance interpretation of two-dimensional (2D) CT slices. Construction of CAD/CAM scaffolds derived from $3 \mathrm{D}$ computer-generated images has found various uses in craniofacial and plastic surgery, and has been particularly valuable when planning complex reconstructive procedures, such as repairs of large traumatic and complex deformities of the temporomandibular joint. Collaborations between engineers, surgeons and prosthetic designers have resulted in efficient exploitation of the available instruments and technologies .

In a previous study, the unit of craniofacial surgery in our department had applied this combined technique in the produce of $\mathrm{EH}$ (hydroxyapatite granules mixed with an epoxide acrylate maleic medical resin molding agent) compound artificial bone implants. Between January 2005 and October 2008, 39 patients with craniomaxillofacial deformities were treated. All the 39 patients were successfully operated on according to the preoperative plans. The results after surgery were satisfactory. One patient with temple augmentation needed secondary surgery to smooth the periphery of the implanted material because of the prominent edge of the implant that can be felt by the patient. Subcutaneous effusion in 2 patients was treated with suction and compressive bandaging. The recovery was satisfying. Implants in the 2 patients operated on through intraoral incisions had to be eventually removed 2 months after the surgeries owing to severe local symptoms of infection such as swelling and pain. All the other patients showed no complications during uneventful postoperative follow-ups.

With the application of CAD/CAM and RP, the implant material is perfectly matched for the skeleton defect. In the discussed case group, the combination of RP and CAD/CAM is applied in the craniomaxillofacial treatment. It has been proved after surgery that customized bone implants adhere to the defected area perfectly, and no migration has been noticed. The adhesion is tight, and the appearance is comparatively symmetrical. As for defect or depression that is close to the midline of the face, there is no mirror image for reference. Proper adjustments for the implant production are made during computerized simulation in accordance with the continuity of the geometric curve of the skeleton, although the patients' own opinions are properly taken at the same time. The postsurgical results were mostly well accepted by the patients. In the EH operation group, 2 patients 

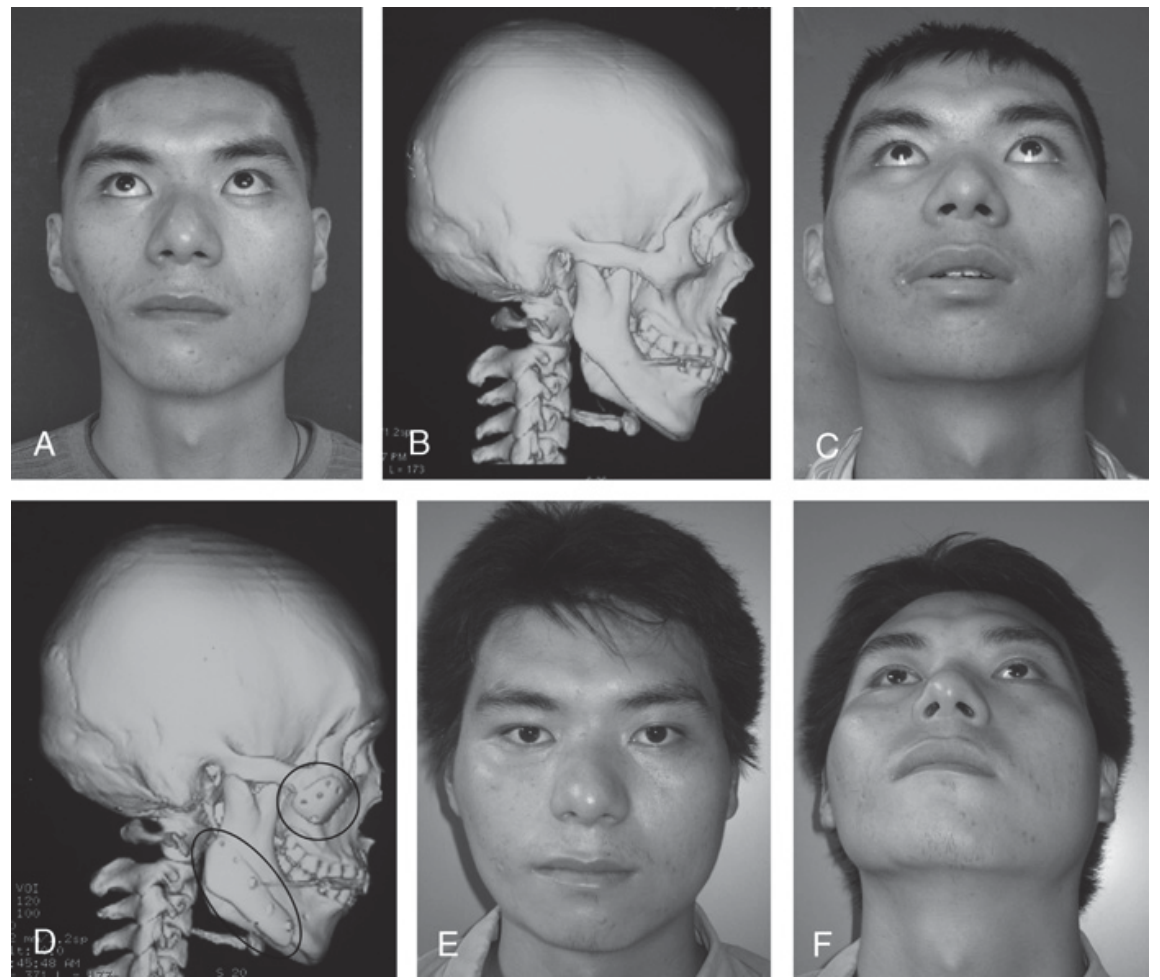

Fiq. 8 A, Preoperative inferior view for patient 1. B, Preoperative three-dimensional CT. C, One-week postoperative inferior view. D, Postoperative three-dimensional CT. E, Anteroposterior view of the same patient after 1 year. F, Inferior view after 1 year.
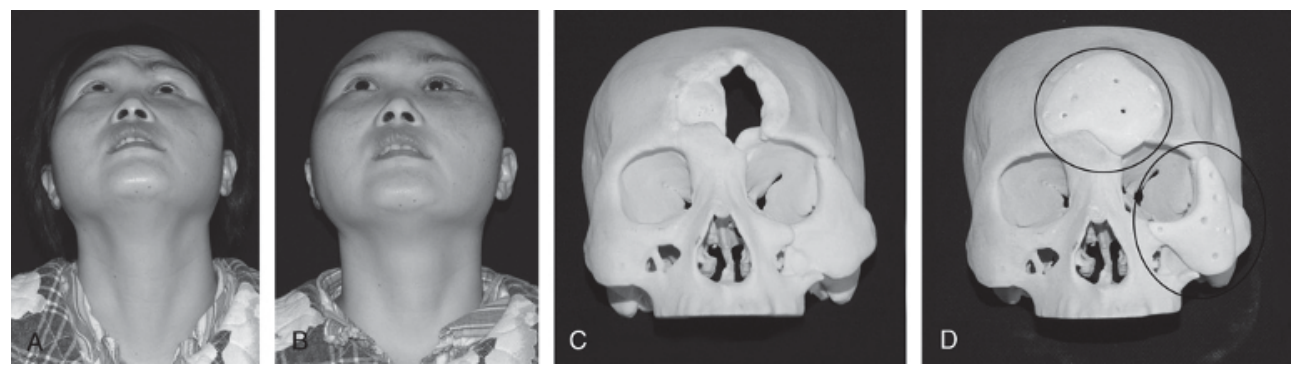

Fig. 9. A, Preoperative inferior view of patient 2. B, Postoperative inferior view (3 mo). C, Three-dimensional skull model. D, Preoperatively made EH compound artificial bone implant.

with temple augmentation were operated on. Usually, a lipoinjection or a Medpor implant is chosen for the reconstructive surgery. However, after sufficient communication with the patients, computerized reconstruction was applied for the design of the $\mathrm{EH}$ compound artificial bone implants to meet the patients' demands. The surgical procedures were easy 
and safe. The implants were placed subperiosteumly. No foreign body rejection or extrusion was noticed during the follow-up.

While studies have investigated the suitability of various materials in the construction of CAD/CAM scaffolds, histological studies focusing on BMSC seeding in scaffolds have demonstrated that PGA/PLA is one of the best materials available for the regeneration of new bone and cartilage. However, sculpting the external volume of the scaffold and generating strategies for its RP using PGA/PLA are significant challenges.

We have described a new method to tailor-make PGA/PLA mandibular condylar scaffolds for bone and cartilage regeneration that ensures excellent morphological alteration and accuracy. A physical replica of the mandible was generated from 3D CT data using $\mathrm{CAD} / \mathrm{CAM}$ and RP, and was used as the positive model in the negative mould technique to prefabricate a PGA/PLA scaffold in the shape of the mandibular condyle. To evaluate the accuracy of the copy thus obtained, a laser scanning system was used. In general, if the difference could be seen in $<90 \%$ of the face after simulated implant placement, this was doomed to be a faithful reproduction; in addition, when aligned, maps of the merged scans showed that, on average, $90 \%$ of the created composite facial scans correlated to the original with an error up to $0.85 \mathrm{~mm}$, which was considered to be clinically acceptable. As for bone reconstruction of craniomaxillofacial features, the tolerance levels reached in our results are more acceptable. A comparison between the copy and the original morphology confirmed the efficacy of this method for accurate reconstruction of craniomaxillofacial features.

Synthetic absorbable implants made of materials such as elastic PGA/PLA can be readily adapted to the shape of a given defect. Because of their resilience, these materials may not sufficiently resist static or dynamic stresses. While each material has its advantages and disadvantages, it must at least accomplish its specified objectives. PGA and PLA are degradable, and their degradation product is weakly acidic. The acid-base neutralization reaction that occurs locally during degradation can prevent aseptic inflammation, maintain acid-base balance and promote osteogenesis. Zhou demonstrated that physiological repair of defects in articular cartilage and the corresponding subchondral bone was achievable using autologous BMSCs and PGA/PLA polymers. This study shows that BMSCs dispersed throughout a PGA/PLA scaffold in in vitro culture, proving that PGA/PLA have excellent cellular compatibility. BMSCs also have multi-lineage differentiation potential, particularly for osteogenic and chondrogenic differentiation, making them ideal seeding cells for tissue engineering.

In summary, our digital medical system enabled the fabrication of a customized PGA/PLA scaffold that very accurately recreated the original anatomical form and also had excellent cellular compatibility. Furthermore, the cost of equipment for this procedure was not high, since RP machines and laser scanners are available at low cost. This digital medical support system may be useful for craniomaxillofacial surgeons when reconstructing complex bony injuries and abnormalities.

\section{References}

[1] Ciocca L, De Crescenzio F, Fantini M, et al. CAD/CAM and rapid prototyped scaffold construction for bone regenerative medicine and surgical transfer of virtual planning: a pilot study. Comput Med Imaging Graph 2009; 33(1): 58-62. 
[2] Klein M, Glatzer C. Individual CAD/CAM fabricated glass-bioceramic implants in reconstructive surgery of the bony orbital floor. Plast Reconstr Surg 2006; 117(2): 565-570.

[3] Yeong WY, Chua CK, Leong KF, et al. Rapid prototyping in tissue engineering: challenges and potential. Trends Biotechnol 2004;22(12): 643-652.

[4] Dean D, Min KJ, Bond A. Computer aided design of large-format prefabricated cranial plates. J Craniofac Surg 2003; 14(6): 819-832.

[5] Peltola SM, Melchels FP, Grijpma DW, et al. A review of rapid prototyping techniques for tissue engineering purposes. AnnMed 2008; 40(4): 268-280.

[6] Ciocca L, Mingucci R, Gassino G, et al. CAD/CAM ear model and virtual construction of the mold. J Prosthet Dent 2007; 98(5):339-343.

[7] Zhou G, Liu W, Cui L, et al. Repair of porcine articular osteochondral defects in nonweightbearing areas with autologous bone marrow stromal cells. Tissue Eng 2006; 12(11):3209-3221.

[8] Xu H, Han D, Dong JS, Shen GX, Chai G, Yu ZY, Lang WJ, Ai ST. Rapid prototyped PGA/PLA scaffolds in the reconstruction of mandibular condyle bone defects. Int J Med Robot. 2010; 6(1):66-72.

[9] Rosen JM, Long SA, McGrath DM, et al. Simulation in plastic surgery training and education: the path forward. Plast Reconstr Surg 2009; 123(2): 729-738; discussion, 739-740.

[10] Hollister SJ. Porous scaffold design for tissue engineering. Nat Mater 2005; 4(7): 518524.

[11] Hutmacher DW, Sittinger M, Risbud MV. Scaffold-based tissue engineering: rationale for computer-aided design and solid free-form fabrication systems. Trends Biotechnol 2004; 22(7): 354-362 [review].

[12] Moroni L, de Wijn JR, van Blitterswijk CA. Integrating novel technologies to fabricate smart scaffolds. J Biomater Sci Polym Ed 2008; 19(5): 543-572.

[13] Wang L, Detamore MS. Tissue engineering the mandibular condyle. Tissue Eng 2007; 13(8): 1955-1971.

[14] Hutmacher DW. Scaffolds in tissue engineering bone and cartilage. Biomaterials 2000; 21(24): 2529-2543.

[15] Kau CH, Richmond S, Zhurov AI, et al. Reliability of measuring facial morphology with a three-dimensional laser scanning system. Am J Orthod Dentofacial Orthop 2005; 128(4): 424-430.

[16] Yu D, Li Q, Mu X, et al. Bone regeneration of critical calvarial defect in goat model by PLGA/TCP/rhBMP-2 scaffolds prepared by low-temperature rapid-prototyping technology. Int J Oral Maxillofac Surg 2008; 37(10): 929-934.

[17] Cao W, Miyamoto Y. Direct slicing from AutoCad solid models for rapid prototyping. Int J Adv Manuf Technol 2003;21:739-742

[18] Muller A, Krishnan KG, Uhl E, et al. The application of rapid prototyping techniques in cranial reconstruction and preoperative planning in neurosurgery. J Craniofac Surg 2003;14:899-914.

[19] Mavili ME, Canter HI, Saglam-Aydinatay B, et al. Use of three-dimensional medical modeling methods for precise planning of orthognathic surgery. J Neurosurg Sci 2008;52:113-116 
[20] Cho YR, Gosain AK. Biomaterials in craniofacial reconstruction. Clin Plast Surg 2004;31:377-385

[21] Baker SB, Weinzweig J, Kirschner RE, et al. Applications of a new carbonated calcium phosphate bone cement: early experience in pediatric and adult craniofacial reconstruction. Plast Reconstr Surg 2002;109:1789-1796

[22] Muhitdin E, Mustafa S, Murat T, et al. Contour restoration of the secondary deformities of zygomaticoorbital fractures with porous polyethylene implant. J Craniofac Surg 2007;18:520-525

[23] Menderes A, Baytekin C, Topcu A, et al. Craniofacial reconstruction with high-density porous polyethylene implants. J Craniofac Surg 2004;15:719-724

[24] Mohamed ED, Tompach PC, Morstad AT, et al. Long-term follow-up of the use of nonporous hydroxyapatite for augmentation of the alveolar ridge. J Oral Maxillofacial Surg 1991;49:257-261

[25] Habal MB, Reddi AH. Bone grafts and bone induction substitutes. Clin Plast Surg 1994;21:525-529

[26] Hashem FK, AI Homsi M, Mahasim ZZ, et al. Laryngotracheoplasty using the Medpor implant: an animal model. J Otolaryngol 2001;30:334-339

[27] Gosain AK, Song L, Riordan P, et al. A 1-year study of osteoinduction in hydroxyapatite-derived biomaterials in an adult sheep model: part I. Plast Reconstr Surg 2002;109:619-630

[28] Gosain AK, Song L, Riordan P, et al. A 1-year study of osteoinduction in hydroxyapatite-derived biomaterials in an adult sheep model: part II. Bioengineering implants to optimize bone replacement in reconstruction of cranial defects. Plast Reconstr Surg 2004;114:1155-1163

[29] Gosain AK, Song L, Riordan P, et al. A 1-year study of hydroxyapatite-derived biomaterials in an adult sheep model: III. Comparison with autogenous bone graft for facial augmentation. Plast Reconstr Surg 2005;116:1044-1052

[30] Schliephake H, Neukam FW. Bone replacement with porous hydroxyapatite blocks and titanium screw implants: an experimental study. J Oral Maxillofacial Surg 1991;49:151-156

[31] Durham S, McComb J, Levy M. Correction of large cranial defects with reinforced hydroxyapatite cement: technique and complications. Neurosurgery 2003;52:842845

[32] $\mathrm{Xu} \mathrm{Y,} \mathrm{Dong} \mathrm{T}, \mathrm{Xu} \mathrm{X}$, et al. Design and fabrication of $\mathrm{EH}$ composite material and evaluation of its biomechanical properties. Acta Acad Med Zuzou 1995;15:17-18

[33] Fan X, Zhang D, Feng S, et al. Late reconstruction and repositioning of enophthalmos of orbital blow-out fracture. China J Ophthalmol 2002;38:644-647

[34] $\mathrm{Mu} \mathrm{X}$, Dong J, Wang W, et al. Epoxide acrylate maleic resin and hydroxyapatite composite material as a hone graft substitute in surgical correction of orbital reconstruction. China J Ophthalmol 1995;31: 447-449

[35] Zins JE, Moreira-Gonzalez A, Papay FA. Use of calcium-based bone cements in the repair of large, full-thickness cranial defects: a caution. Plast Reconstr Surg 2007;120:1332-1342

[36] Matic DB, Manson PN. Biomechanical analysis of hydroxyapatite cement cranioplasty. J Craniofac Surg 2004;15:415 
[37] Bianchi SD, Ramieri G, De Gioanni PP, et al. The validation of stereolithographic anatomical replicas: the authors' own experience and a review of the literature [in Italian]. Radiol Med 1997;94:503-510

[38] Choi JY, Choi JH, Kim NK, et al. Analysis of errors in medical rapid prototyping models. Int J Oral Maxillofac Surg 2002;31:23-32

[39] Matic D, Phillips JH. A contraindication for the use of hydroxyapatite cement in the pediatric population. Plast Reconstr Surg 2002;110:1-5 


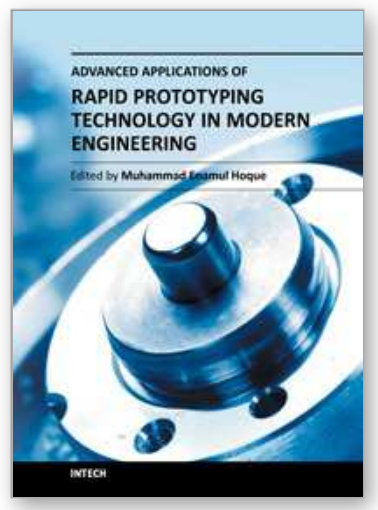

\section{Advanced Applications of Rapid Prototyping Technology in Modern Engineering}

Edited by Dr. M. Hoque

ISBN 978-953-307-698-0

Hard cover, 364 pages

Publisher InTech

Published online 22, September, 2011

Published in print edition September, 2011

Rapid prototyping (RP) technology has been widely known and appreciated due to its flexible and customized manufacturing capabilities. The widely studied RP techniques include stereolithography apparatus (SLA), selective laser sintering (SLS), three-dimensional printing (3DP), fused deposition modeling (FDM), 3D plotting, solid ground curing (SGC), multiphase jet solidification (MJS), laminated object manufacturing (LOM). Different techniques are associated with different materials and/or processing principles and thus are devoted to specific applications. RP technology has no longer been only for prototype building rather has been extended for real industrial manufacturing solutions. Today, the RP technology has contributed to almost all engineering areas that include mechanical, materials, industrial, aerospace, electrical and most recently biomedical engineering. This book aims to present the advanced development of RP technologies in various engineering areas as the solutions to the real world engineering problems.

\section{How to reference}

In order to correctly reference this scholarly work, feel free to copy and paste the following:

Dong Han, Jiasheng Dong, De Jun Cao, Zhe-Yuan Yu, Hua Xu, Gang Chai, Shen Guo-Xiong and Song-Tao Ai (2011). Usage of Rapid Prototyping Technique in Customized Craniomaxillofacial Bone Tissue Engineering Scaffold, Advanced Applications of Rapid Prototyping Technology in Modern Engineering, Dr. M. Hoque (Ed.), ISBN: 978-953-307-698-0, InTech, Available from: http://www.intechopen.com/books/advanced-applicationsof-rapid-prototyping-technology-in-modern-engineering/usage-of-rapid-prototyping-technique-in-customizedcraniomaxillofacial-bone-tissue-engineering-scaff

\section{INTECH}

open science | open minds

\section{InTech Europe}

University Campus STeP Ri

Slavka Krautzeka 83/A

51000 Rijeka, Croatia

Phone: +385 (51) 770447

Fax: +385 (51) 686166

www.intechopen.com

\section{InTech China}

Unit 405, Office Block, Hotel Equatorial Shanghai

No.65, Yan An Road (West), Shanghai, 200040, China 中国上海市延安西路65号上海国际贵都大饭店办公楼405单元

Phone: +86-21-62489820

Fax: +86-21-62489821 
(C) 2011 The Author(s). Licensee IntechOpen. This chapter is distributed under the terms of the Creative Commons Attribution-NonCommercialShareAlike-3.0 License, which permits use, distribution and reproduction for non-commercial purposes, provided the original is properly cited and derivative works building on this content are distributed under the same license. 